\title{
Sobre uma pintura inseticida para o controle de Triatoma infestans, na Bolívia
}

\author{
About an insecticidal paint for controlling Triatoma infestans, in Bolivia
}

\author{
João Carlos Pinto Dias ${ }^{1}$ e A. Jemmio ${ }^{2}$
}

\begin{abstract}
RESUMO
Avaliações preliminares sobre uma pintura inseticida à base de diazinon, clorpirifós e piriproxifen em formulação micro-encapsulada (Inesfly 5A IGR $\left({ }^{\circledR}\right)$ mostrou efetiva e persistente atividade contra Triatoma infestans intra e peridomiciliar, numa região altamente infestada do Chaco Boliviano. Ressaltam, além disso, a boa manuseabilidade do produto e o bom aspecto deixado pela pintura em casas e anexos tratados, bem como uma excelente aceitação pela população e autoridades sanitárias locais, o que estimula novas investigações e o emprego do produto em maior escala e contra outros vetores da doença de Chagas.
\end{abstract}

Palavras-chaves: Pintura inseticida. Controle. Triatoma infestans. Doença de Chagas.

\begin{abstract}
Preliminary evaluations of an insecticidal paint based on diazinon, chlorpyrifos and pyriproxyfen in a micro-encapsulated formulation (Inesfly $5 \mathrm{~A}$ IGR $\left.{ }^{\circledR}\right)$ have shown that it has effective and persistent activity against Triatoma infestans inside homes and in areas surrounding homes, in a highly infested region of the Bolivian Chaco. Furthermore, the evaluations have highlighted that the product presents good handling characteristics and gives a good appearance to houses and outhouses that have been treated, and that its acceptance among the population and the local sanitary authorities is excellent. This encourages new investigations and the use of the product on a larger scale and against other vector species for Chagas disease.
\end{abstract}

Key-words: Insecticidal paint. Control. Triatoma infestans. Chagas disease.

Entre os atuais desafios para consolidar a luta contra a doença de Chagas humana nas Américas, a luta antitriatomínica representa grande prioridade em todos os países endêmicos, seja na chamada fase de ataque, seja na de vigilância epidemiológica ${ }^{3910}$. Em que pese a considerável eficácia dos modernos inseticidas piretróides, largamente difundidos, detectam-se amiúde alguns problemas de custo e efetividade em várias áreas trabalhadas, mormente em função de sua reduzida atividade no peridomicílio e de descontinuidade operativa dos programas de desinsetização, por várias razões, especialmente de natureza administrativa. Acresce ainda, em anos recentes, o surgimento de tolerância e resistência aos piretróides por algumas populações de triatomíneos, detectada particularmente ao Norte da Argentina e Sul da Bolívia $^{3}{ }^{10}$. A presente nota é fruto de algumas observações preliminares com um novo produto, a pintura inseticida Inesffly 5A IGR (I 5A IGR). Este corresponde a uma tinta vinílica de base aquosa, micro encapsulada em uma matriz de carbonato de cálcio e resina, sendo ingredientes ativos (IA) o diazinon (1,5\%) e o clorpirifós $(1,5 \%)$, em combinação com um regulador de crescimento de insetos, o piriproxifen $(0,063 \%)^{56}$.
A microcápsula possui uma estrutura morfológica relativamente simples, sendo composta por dois elementos claramente diferenciados: o núcleo ativo, envolto por uma delgada armação polimérica. 0 processo de obtenção é complexo, para que os princípios ativos sejam introduzidos na matriz polimérica e se consiga sua liberação gradual. 0 núcleo possui uma natureza líquida, incorporando os sólidos dos IA e o pigmento. 0 produto se apresenta em suspensão de microcápsulas que oscilam entre um e várias centenas de micrômetros.

Não é a primeira vez que se tenta uma pintura inseticida contra triatomíneos. Na década de 1980, foi ensaiada a pintura francesa Artilin, com base em piretróides, seguindo-se um produto do Prof. Alfredo Oliveira Filho, do Rio de Janeiro, com base em fosforados, esta última patrocinada pelo TDR/OMS ${ }^{8}$. Ambas mostraram bom efeito residual em testes de campo e laboratório, mas não se viabilizaram comercialmente no Brasil e outros países endêmicos, por problemas também de formulação (em termos de estabilidade e viscosidade), não chegando ao emprego em larga escala.

\footnotetext{
1. Centro de Pesquisas René Rachou, Fundação Oswaldo Cruz, Belo Horizonte, MG. 2. Inesfly S.L, Engenharia de Saúde, Valencia, Espanha (Ex-coordenador do Programa Nacional de Doença de Chagas da Bolívia).

Endereço para correspondência: Dr. João Carlos Pinto Dias. Centro de Pesquisas René Rachou/FIOCRUZ, Belo Horizonte, MG.

Tel: $55313349-7700$

e-mail: jcpdias@cpqrr.fiocruz.br

Recebido para publicação em: 23/10/2007

Aceito em: 21/11/2007
} 
0 produto ora em observação foi desenvolvido em Valencia, Espanha, com ação comprovada contra mosquitos em geral, ácaros, himenópteros e ortópteros (Blatella germânica e Periplaneta americana $)^{5}$. A principal ação da pintura é de cunho inseticida, atuando os ingredientes ativos por contato, em lenta liberação e efeito residual, estimado em mais de 24 meses. Ocorrem também ação repelente e efeito análogo ao dos hormônios juvenilizantes, dificultando ou impedindo as ecdises dos estádios ninfais Estudos bem conduzidos na Espanha (Instituto de Salud Carlos III) demonstraram a segurança da pintura em termos de ação não irritante (ocular, dérmica e sistêmica), não citotóxica e não mutagênica ${ }^{36}$. Em Cali, Colômbia, o Centro Internacional de Entrenamiento e Investigaciones Médicas (CIDEIN), classificou o mesmo produto na categoria IV de toxicidade dérmica aguda, na categoria IV de toxicidade inalatória aguda e na Categoria III de toxicidade oral aguda. Nestes ensaios, a pintura também não apresentou sensibilização cutânea ${ }^{2}$. Testes de colinesterase nos aplicadores e população também se mostraram negativos, no conjunto concluindo tratar-se de um produto praticamente sem risco para a população exposta, ambiente e aplicadores. Complementarmente, informa-se que a I 5A IGR está aprovada para uso domi-sanitário em países como a Espanha, Costa Rica, Argentina, Colômbia e México, com patente registrada nos Estados Unidos, Inglaterra, França, Espanha, Alemanha, Argentina e Brasil ${ }^{5}$.

Os primeiros ensaios com a pintura I 5A IGR na prevenção da doença de Chagas humana foram realizados nos últimos 7 anos no Chaco Boliviano, tendo mostrado boa efetividade contra os triatomíneos e nenhuma toxicidade para a populaçã $0^{6}$. Não obstante, com alguns problemas metodológicos e falta de grupos controles bem estabelecidos, os produtores resolveram refazer a pesquisa na área de Camiri, Sudeste Boliviano, a partir de 2006. Novos ensaios se programam para Santiago del Estero e La Rioja (Argentina), também estando planejados ensaios de campo e laboratório para algumas espécies brasileiras. A presente nota é resultado de uma visita de inspeção solicitada pelos produtores, a Camiri, julho de 2007, uma região historicamente sempre infestada por Triatoma infestans em alta intensidade ${ }^{4}$. Os resultados e impressões a seguir são preliminares, mas já esboçam uma perspectiva bastante favorável em termos de aceitação, aplicabilidade e efetividade. Além da revisão de matérias publicadas e dados ainda inéditos, houve dois dias inteiros de visita à periferia e zona rural de Camiri, com ampla liberdade para conversações com a população, com técnicos e com pesquisadores envolvidos, além de vistoria pessoal a mais de sessenta unidades domiciliares trabalhadas com o novo produto. A função da presente nota é chamar a atenção para um produto promissor na profilaxia da doença de Chagas, já em vias de teste em outros países. Telegraficamente, por tópicos analisados, pode-se destacar:

a) Trabalhos prévios: foram realizados em larga extensão do Chaco Boliviano, somando várias centenas de unidades domiciliares tratadas. Os dados mais interessantes entre os disponíveis reportam-se a Camiri, com altitude de $800 \mathrm{~m}$ acima do nível médio do mar, a uma latitude Sul de $20^{\circ}, 2$ minutos e 21 segundos, com uma longitude de $63^{\circ}, 31$ minutos e
13 segundos, sendo há poucos anos uma das zonas endêmicas mais infestadas por Triatoma infestans da Bolívia. Os dados mais ilustrativos provêm de uma aplicação há 72 meses em comunidades rurais de Camiri, com quatro grupos de vivendas de pau a pique e/ou adobe, a saber: Grupo $\mathrm{I}=142$ vivendas rebocadas e com a pintura realizada pela equipe técnica, nas comunidades de Tejería, Pipi Parienda, Itiyuru e Guasuiga; Grupo II = 45 vivendas pintadas pela própria população, na localidade Guirarapo; Grupo III = 31 vivendas pintadas pela equipe técnica no bairro periférico denominado Panamericano, e, Grupo IV $=28$ vivendas sem pintura, eventualmente rociadas com piretróides pelo Programa Nacional, em Urundayti ${ }^{6}$. A Tabela 1 resume os dados de infestação intradomiciliar, no período.

Tabela 1 - Porcentagens de infestação triatomínica intradomiciliar em quatro grupos de vivendas da região de Camiri, Bolívia, pintadas ou não com o produto Inesfly e seguidas por 72 meses.

\begin{tabular}{lcccccc}
\hline & \multicolumn{5}{c}{ Avaliações sucessivas, em meses (\% infestação) } \\
\cline { 2 - 7 } Grupo & pré-tratamento & imediato & 9 meses & 12 meses & 24 meses & 72 meses \\
\hline I & 89,4 & 0 & 0 & 15,4 & 6,4 & 2,1 \\
II & 68,9 & 0 & NR & 5,1 & 5,6 & 6,6 \\
III & 96,7 & 0 & 3,2 & 3,3 & NR & 0 \\
IV & 92,9 & NR & NR & $91,3^{*}$ & $56,0^{*}$ & 25,0 \\
\hline
\end{tabular}

*expurgado com piretróide, NR: não realizado.

b) Impressões atuais em cerca de 60 unidades domiciliares visitadas, nas comunidades supra mencionadas, com pintura realizada entre 5 e 9 meses passados:

- Taxas de infestação: não foi detectada nenhuma vivenda infestada por triatomíneos ou com vestígios recentes dos mesmos, tanto no intra como no peridomicílio. A população interrogada afirma unanimemente que não somente as vinchucas, mas outros artrópodes como baratas, aranhas e moscas também desapareceram após a aplicação da tinta. Praticamente em todas as vivendas visitadas se detectaram vestígios antigos de triatomíneos, especialmente sob forma de dejeções secas e de exúvias. Deu-se especial atenção ao exame de galinheiros (abundantes na região e geralmente muito rústicos), estando todos negativos.

- Aspecto geral das casas: muito bom, com a pintura preservada, mesmo nas vivendas mais pobres de pau a pique. Não se detectou odor estranho ou desagradável devido à pintura, em nenhuma casa ou anexo inspecionado (Figura 1).

- Aspecto da pintura em ecótopos peridomiciliares: bastante preservada e aparentemente com atividade inseticida persistente, pela não detecção de insetos e outros artrópodes. Observou-se a boa adesão da pintura em superfícies porosas de barro, madeira ou tijolo, sugerindo-se que sobre estas sejam feitos testes biológicos. Em anexos muito complexos, como cercas, muros e depósitos de cereais, observou-se o cuidado dos aplicadores em pintar locais estratégicos e de passagem de possíveis insetos, com prioridade (Figura 2). 


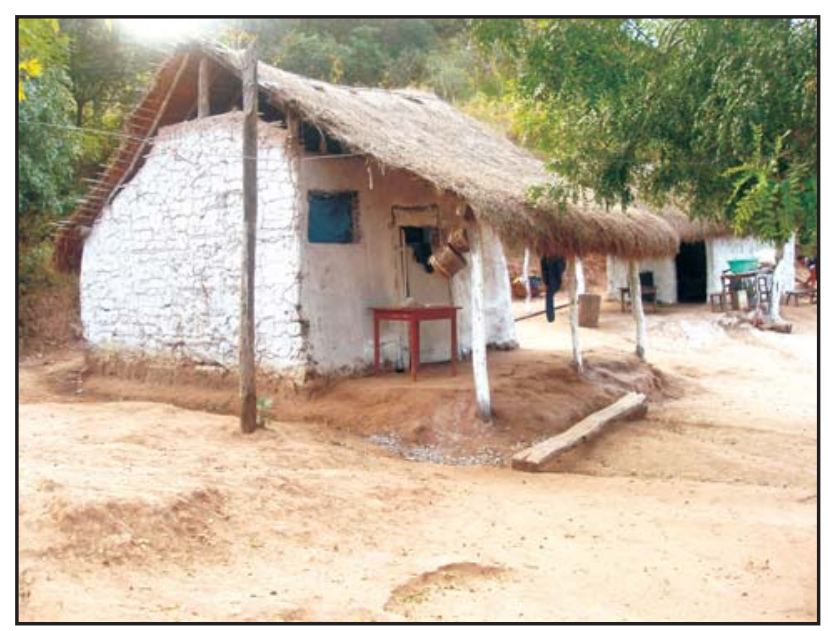

Figura 1 - Aspecto externo de casa rústica pintada com Inesfly bá mais de seis meses (Camiri 2007).

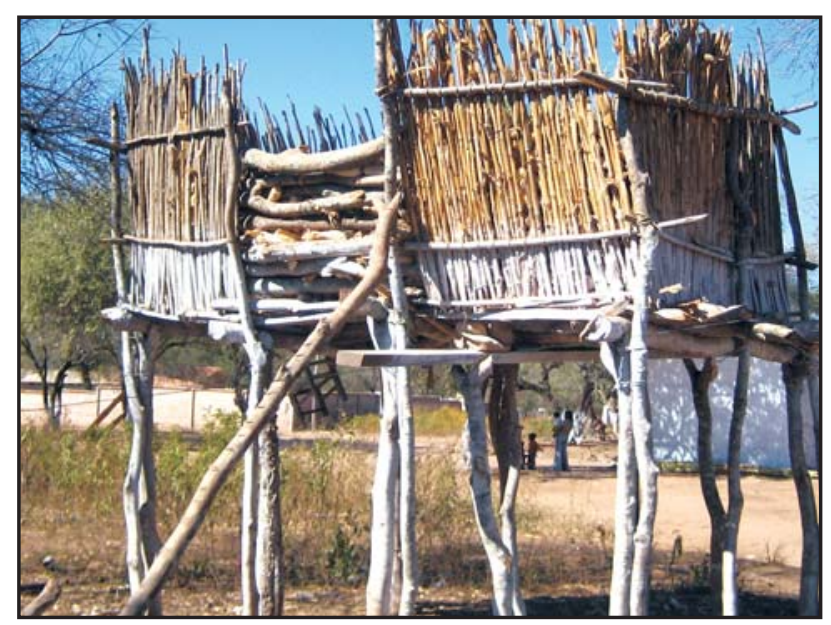

Figura 2 - Aspecto de pintura em peridomicílio (depósito rústico de grãos, Camiri 2007).

- Satisfação da população e efeitos indesejáveis: há unanimidadena satisfação, tanto em função do desaparecimento de insetos como pelo visível melhoramento estético das pobres vivendas. Informe-se que a matriz da pintura é branca, mas pode ser colorida com pigmentos de quaisquer cores, à escolha dos moradores, o que é muito estimulante, inclusive em termos de auto-estima e de incentivo posterior à higiene. Os moradores tiveram grande grau de participação em todo o processo de pintura, segundo eles mesmos, o que é muito importante no contexto do melhoramento e manutenção da vivenda ${ }^{1}$. Não se registrou nenhuma reclamação sobre efeitos indesejáveis, especialmente de natureza alérgica ou tóxica sistêmica, em moradores ou aplicadores.

- Satisfação e parceria de autoridades governamentais e outras instituições: os trabalhos estão sendo levados a cabo com grande satisfação e interesse dos dirigentes regionais e comunitários. Ao ensejo do aniversário de Camiri, uma equipe do Projeto desfilou na praça central da cidade, sendo entusiasticamente ovacionada. A propósito, o Projeto vem sendo acolhido e tem sede no edifício próprio da ONG Caritas Diocesana, o que the garante credibilidade e grande facilidade de ação.
Concluindo, indubitavelmente, o produto e a estratégia utilizados apresentam clara ação triatomicida, a par de um desdobramento estético e de elevação da auto-estima da população, sendo bastante promissor o seu emprego em zonas de transmissão vetorial da esquizotripanose. Não se registraram efeitos indesejáveis, esperando-se que, pelas características do produto, seu efeito residual alcance dois anos ou mais, assim possibilitando economia na re-aplicação de pesticidas convencionais. Em particular, na região visitada, a efetividade no peridomicílio mostrou-se aparentemente muito alta, conferindo grande vantagem sobre os inseticidas convencionais, sendo muito importante um seguimento rigoroso a mais longo prazo. Como complemento, será importante a repetição dos experimentos em outras regiões e países, o que está sendo providenciado para a Argentina, assim como para outras espécies de triatomíneos (ensaios programados para 0 Brasil). Igualmente serão muito válidos os estudos de custo $\mathrm{e}$ benefício, como forma de aquilatar a viabilidade do produto em maior escala. Também, se considera oportuna a formulação de pinturas com outros ingredientes ativos, especialmente piretróides, como já em andamento pela Firma Produtora, com vistas a eventuais problemas de resistência e maior ação residual. Finalmente, é muito desejável o acompanhamento dos projetos em andamento por autoridades bolivianas e pela OPS/OMS, tanto com o objetivo do registro definitivo do produto, como para definir sua aplicabilidade em outras regiões endêmicas e em outras situações epidemiológicas.

\section{REFERÊNCIAS}

1. Briceño-León R. La casa enferma.. Sociología de la enfermedad de Chagas. Ediciones Capriles, Caracas, 1990.

2. Centro Internacional de Entrenamiento e Investigaciones Médicas (Cali, Colombia). Protocolos de Analisis toxicológicas del producto Inesfly Pintura 5 A IGR, 2004.

3. Dias JCP. Controle da doença de Chagas. In: Dias JCP, Coura JR (eds) Clinica e Terapêutica da doença de Chagas. Uma abordagem prática para 0 clínico geral. Editora Fundação Oswaldo Cruz, Rio de Janeiro, p. 453-468, 1997.

4. Guillén G. El control de la enfermedad de Chagas en Bolívia. In: Silveira AC (org) El control de la Enfermedad de Chagas en los Países del Cono Sur de América. Faculdade de Medicina do Triângulo Mineiro, Uberaba, p. 109-144, 2002.

5. Lopez J, Jimenez R, Mateo MP, Moreno J, Oltra MT. Efficacy of Inesfly 5A IGR paint against Periplaneta americana in sewers in Canary Islands (Spain). Proocedings of the $3^{\text {rd }}$ International Conference on Urban Pests, 1999.

6. Mateo MP, López J. Inesfly 5A IGR: una alternativa para el control de Triatominos vectores de la enfermedad de Chagas. Experiencias en el Chaco Boliviano. Mimeografado, 2006.

7. Olcina B. Pinturas Insecticidas. Tesis Doctoral. Universidad de Valencia, España, 1999.

8. Oliveira Filho A. Uso de nuevas herramientas para el control de triatominos en diferentes situaciones entomológicas en el Continente Americano. Revista da Sociedade Brasileira de Medicina Tropical 30: 41-46, 1997.

9. Schofield CJ. Global collaboration for development of pesticides for Public Health. World Health Organization/WHOPES, Geneva, 2001.

10. World Health Organization. Control of Chagas Disease. WHO Technical Report Series 905, World Health Organization, Geneva, 2002. 